\title{
Protocol for Root Canals' Irrigation in Endodontic Practice in Ivory Coast: A Survey of 100 Dentists
}

\author{
Adou-Assoumou $\mathrm{M}^{*}$, Krah-Sinan $\mathrm{AA}^{1}$, Koffi-Gnagne $\mathrm{Y}^{1}$, Bane $\mathrm{K}^{2}$, Faye $\mathrm{B}^{2}$, and Diemer $\mathrm{F}^{3}$ \\ ${ }^{1}$ Endodontic and Restorative Department, Felix Houphouet Boigny University of Abidjan, Ivory Coast \\ ${ }^{2}$ Endodontic and Restorative Department, Cheikh Anta Diop University of Dakar, Sénégal \\ ${ }^{3}$ Endodontic and Restorative Department, Faculty of Dental Surgery 3 Chemin des Maraichers, France
}

*Corresponding author: Pr. Adou-Assoumou M, Endodontic and Restorative Department, Félix Houphouet Boigny University of Abidjan, BP 612 Abidjan 22, Ivory Coast, Tel: +22507938976, E-mail: adoussma@ yahoo.fr

Citation: Adou-Assoumou M, Krah-Sinan AA, Koffi-Gnagne Y, Bane K, Faye B, et al. (2017) Protocol for Root Canals' Irrigation in Endodontic Practice in Ivory Coast: A Survey of 100 Dentists. J Dent Oral Care Med 3(3): 303

Received Date: September 23, 2017 Accepted Date: December 27, 2017 Published Date: December 29, 2017

\begin{abstract} consultations and advanced stages of pathologies characterized the endodontics.

Objective: This work aimed to assess root canal irrigation procedures used in Ivory Coast; an unprecedented study in the country. knowledge, attitudes and practices related to root canal irrigation. the device before the ejection of the product.

Conclusion: As a result, in Ivory Coast, irrigation procedures do not always comply with standards.

Keywords: Dentist; Disinfection; Endodontics; Ivory Coast; Root canal irrigation

List of abbreviations: KOP: Knowledge; Outlook and Practices; EDTA: ÉthylèneDiamineTétra-Acétique
\end{abstract}

Introduction: In endodontics, a chemo-mechanical preparation is used to disinfect the root canal system. However, due to limitations of endodontic devices, which shape the main canal, this preparation is supplemented by irrigation solutions. In Ivory Coast, late

Methods: One hundred dental surgeons practicing in the private and the public sector in Abidjan received a questionnaire to assess the

Results: Results show that practitioners (77\%) commonly use sodium hypochlorite solutions for irrigation. However, $76 \%$ of them do not know the recommended concentration. Besides, it is dental auxiliaries (73\%) who prepare the solution, whereas only half of them know the dilution proportions. Half of the respondents use syringes and intramuscular injection needles while $52 \%$ do not withdraw

\section{Introduction}

The principal aim of any endodontic treatment is to eradicate microorganisms that invade the canal system [1,2]. This disinfection is essentially based on a chemo-mechanical preparation where limitations of endodontic devices, which shape the main canal, are made up for by irrigation solutions. The latter cleans the whole canal system, provided that a surgical sequence is met within an aseptic setting. It starts with irrigation as soon as the access cavity opens, during and at the end of the canal preparation, to remove the dental sludge generated by shaping devices.

While devices shape the main canal, irrigation solutions clean the entire canal system out $[3,4]$. Indeed, in a properly prepared canal, devices are not needed in some parts of the walls. Similarly, these devices cannot access crypts, such as anfractuosities of the ductal system, isthmuses and lateral or secondary canals, which are likely to harbor bacteria. To remedy these issues and since all required objectives cannot be met with a single solution, numerous irrigation solutions are developed. Thus, highlighting the irrigation action during endodontic preparations and explaining how to potentiate these antibacterial solutions is essential. It is the chemical part of canal cleansing and the only effective weapon against the complexity of the root canal system. Without irrigation, organic debris in the endodontic cavity, or those generated during its preparation, are likely to decompose and promote microbial proliferation, a periapical infection vector.

Sodium hypochlorite is still the reference irrigation solution for endodontics and must be combined with an EDTA solution at the end of the preparation [5-8]. 
In Ivory Coast, late consultations and advanced pathologiescharacterize the dentistry practice in general and the endodontics in particular.

This work aimed to assess root canal irrigation procedures used in Ivory Coast, an unprecedented study on this theme in the country. This country has 715 dental surgeons regularly registered on the board of the National Council of the College of Dentists. Among these registered, 627 are active throughout the territory of which 500 are located in the district of Abidjan (National Council of the College of Dentists-Dentists of Côte d'Ivoire (CNOCDCI) Update of the staff of Surgeon-Dentists of Côte d'Ivoire 03 March 2016).

In this workforce, the country has only nine endodontists who are teachers in the Training and Research Unit in OdontoStomatology. All these specialists were excluded from this study. Only private or public general practitioners from the district of Abidjan were included.

\section{Methods and Materials}

Participants received a survey form containing 31 items divided into five subgroups:

- General information

- Endodontic treatments frequency

- Irrigation devices and techniques

- Irrigation products

- Irrigation procedures.

One hundred dental surgeons practicing in the private and the public sector in Abidjan participated in this study. It was a KOP (Knowledge, Outlook and Practices) survey carried out from June 2016 to October 2016. Participants are selected from a poll of private dental practices, members of the Council of the Order of Dentists-Surgeonsand an exhaustive census of all public facilities with a dental practice. In both cases, the questionnaire was self-administered.

The survey excluded teachers from the Endodontics Conservative Odontology unit as well as practitioners outside of Abidjan. Collected data were processed with an Excel spreadsheet and some criteria coded to facilitate the data entry. The SPSS 18.0 software was used for statistical calculations and the threshold significance set at $\mathrm{p}<0.05$.

\section{Results}

\section{Sample characteristics}

This study targeted non-specialist general practitioners in endodontics of the district of Abidjan. The country's endodontic specialists, nine in all, were excluded from this study. Male practitioners predominate the survey with a sex ratio of $2 / 1$. In the survey, $58 \%$ of practitioners have more than five years of professional experience and $42 \%$ with 1 to 5 years of seniority.

The monthly endodontic treatment frequency ranged from 1 to 5 for $36 \%$ of practitioners, 6 to 10 for $26 \%$, and 11 to 20 for $29 \%$.

Results of the average duration of a canal preparation session are presented in Table 1.

The last preparation device determines the apical diameter of the final preparation: $34 \%$ of practitioners use a file 30 to complete the preparation while $37 \%$ use a 35 and $18 \%$ a file over 35 .

According to $10 \%$ of surveyed practitioners, the diameter of the preparation depends on the tooth.

\begin{tabular}{|c|c|c|}
\hline $\begin{array}{c}\text { Average duration of } \\
\text { a canal preparation } \\
\text { session (min) }\end{array}$ & Number & Percentage(\%) \\
\hline$<15$ min & 11 & 11 \\
\hline 15 to 20 min & 59 & 59 \\
\hline 21 to 25 min & 14 & 14 \\
\hline 26 to 30 min & 11 & 11 \\
\hline$>30$ min & 2 & 2 \\
\hline Did not answer & 3 & 3 \\
\hline Total & 100 & 100 \\
\hline
\end{tabular}

Table 1: Average duration of a canal preparation session

\section{Irrigation devices and technique}

All surveyed practitioners use the irrigation technique during preparations. Devices used are listed in Table 2. 


\begin{tabular}{|c|c|c|}
\hline Irrigation devices & Number & Percentage(\%) \\
\hline Pipette & 22 & 13 \\
\hline $\begin{array}{c}\text { Intramuscular } \\
\text { syringe }\end{array}$ & 83 & 50 \\
\hline Endodontic syringe & 12 & 7 \\
\hline Insulin syringe & 41 & 25 \\
\hline Anesthesia syringe & 8 & 5 \\
\hline Total & 166 & 100 \\
\hline
\end{tabular}

Table 2: Distribution of surveyed practitioners according to irrigation devices used

\section{Irrigation products}

All surveyed practitioners use sodium hypochlorite $(\mathrm{NaOCl})$ solution for canal disinfection. Moreover, some use hydrogen peroxide (9.2\%), Chlorhexidine (4.6\%), physiological serum $(5.4 \%)$ or plain water $(3.8 \%)$. The NaOCI solution is used by $77 \%$ of surveyed practitioners. While $9 \%$ of them pre-dose it, $14 \%$ use it as it is or pre-dosed.

Regarding the recommended concentration of the $\mathrm{NaOCl}$ solution for endodontics, $76 \%$ of surveyed practitioners ignore it. Only $12 \%$ prepare the solution themselves, while dental assistants prepare the solution for $73 \%$ of them and for $15 \%$ it was either the assistant or practitioners themselves. Regarding the dilution proportions, $50 \%$ of surveyed practitioners knew it versus $22 \%$ who did not and $28 \%$ did not provide an answer. The shelf life of the diluted product is 24 hours for $56 \%$ of surveyed practitioners, more than 24 hours for $33 \%$, and $11 \%$ did not provide an answer. The average amount of solution used per canal preparation session was 10 to $20 \mathrm{ml}$ for $66 \%$ of surveyed dental surgeons, $30 \mathrm{ml}$ for $13 \%$ and $5 \mathrm{ml}$ for $12 \%$; $9 \%$ did not provide an answer. Chelating agents are used by $29 \%$ of surveyed practitioners while $71 \%$ do not and EDTA is the most used chelator, accounting for $93 \%$ of agents' users while $7 \%$ use other acidic products.

\section{The irrigation procedure}

When the needle touches the canal walls before the ejection of the product, $48 \%$ of surveyed practitioners remove it while $58 \%$ do not. The irrigation solution is refreshed by $82 \%$ after each instrument pass and $18 \%$ after 2 to 3 passes. The average duration of final irrigation is listed in Table 3.

\begin{tabular}{|c|c|c|}
\hline $\begin{array}{c}\text { Duration of } \\
\text { final irrigation }\end{array}$ & Number & $\begin{array}{l}\text { Percentage } \\
(\%)\end{array}$ \\
\hline $1 \mathrm{~min}$ & 47 & 47 \\
\hline 1 to $2 \min$ & 33 & 33 \\
\hline 3 to $5 \mathrm{~min}$ & 15 & \\
\hline$>5 \min$ & 2 & 2 \\
\hline Did not answer & 3 & 3 \\
\hline Total & 100 & 100 \\
\hline
\end{tabular}

\section{Discussion}

\section{Sample}

To carry out this study, we surveyed 100 practicing dental surgeons in Abidjan, Ivory Coast. After receiving all fact sheets and from the badly filled out and/or lost cards we wound up with this sample which makes it fairly representative of the 700 Ivorians dental surgeons regularly registered with the National College of Dental Surgeons.

\section{Endodontic treatment}

The study's results show that endodontic treatments are performed at a variable frequency. Only $36 \%$ of surveyed practitioners perform between 1 and 5 treatments per month. This could be due either to the cost of this procedure, or consultations being put off with highly deteriorated dental structures, or because practitioners prefer procedures they believe more clearcut for them.

The duration of a canal preparation session is 15 to 20 minutes on average for $59 \%$ of surveyed practitioners; enough time for a single rooted tooth or even a multiple-rooted one with straight and wide canals, regardless of the canal preparation technique used. When dealing with anatomical difficulties, however, this time may seem insufficient. For an optimal disinfection, 60 minutes, on average, is recommended $[9,10]$. 
However, this study shows that a final preparation diameter of 30/100 or more is acceptable regardless of the pulp diagnosis. Yet, for a deep penetration of the irrigation needle, a higher conicity is recommended for the preparation [11]. In this survey, the preparation was manually done with $2 \%$ conicity files.

\section{Irrigation devices and technique}

Surveyed practitioners commonly use the passive irrigation with syringe method. Nevertheless, contrary to recommendations [12], they frequently use intramuscular injection (50\%), insulin (25\%) or anestheticsyringes instead of endodontic syringes (7\%). The drawback, in this case, is that the needle does not sufficiently penetrate into the canal, either because its diameter is too large or too short, or cannot be blocked when it is the anesthetic syringe which tip-cap is usually smooth. In endodontics, because of the use of hypochlorite, it is necessary to utilize a syringe with a locking system to prevent disconnection of the needle from the syringe. Therefore, irrigation aims are not achieved. Indeed, studies have shown that the irrigation solution is not projected beyond $1 \mathrm{~mm}$ from the tip of the needle [13]. Yet, with infected teeth, the harmful bacteria are in fact located in these last few apical millimeters [14]. Thus, a deeper penetration into the apical third is necessary for an optimal disinfection [12]. Likewise, at the end of the preparation, an active irrigation is recommended to boost the disinfecting action of the sodium hypochlorite [15].

\section{Irrigation products used}

In this study, all surveyed practitioners use sodium hypochlorite for canal irrigation. Nevertheless, few of them, sometimes, use other products, such as Chlorhexidine (4.6\%), hydrogen peroxide (9.2\%), physiological serum or plain water (9.2\%). Of those using the $\mathrm{NaOCl}, 77 \%$ pre-dilute the solution, although the majority (76\%) of them does not know the recommended concentration for endodontic applications, which is $2.5 \%$. Moreover, it is chair assistants (73\%) who prepare the irrigation solution, whereas only half of them know the dilution proportion. This becomes an issue regarding the proper use of this product. Consequently, commonly used household cleaning solutions measured out $8 \%$ or $12 \%$ may contain other compound aimed at improving their stability and cleaning properties. They may also contain perfumes which are more or less likely harmfulto the oral cavity [14].

"Random" dilution can increase adverse effects and can make the irrigation solution ineffective, as well. It is therefore recommended, for a better quality of care, to document on vials the concentrations and expiration date information on pre-dosed solutions specifically formulated for endodontic irrigation. Only $9 \%$ of surveyed practitioners took these precautionary measures. These later allow a better control of the dilution, the storage, and the concentration of solutions.

Our results show that chelating agents are randomly used. Only $29 \%$ used these agents while the majority (93\%) uses it in the form of EDTA. This finding is contrary to the literature's recommendations which suggest a NaOCl-EDTA combination $[11,16]$.

\section{The irrigation procedure}

Withdrawing the device prior to the ejection of the irrigation solution allows debris torise occlusally and to avoid pressure in the apical directionwith the risk of a lesion to periapical structures [5,17-20]. Yet, more than half (52\%) of surveyed practitioners do not actually withdraw the device which is necessary to prevent iatrogenic periodontitis when using endodontic needles.

Regarding the irrigation solution refreshment frequency after each pass of the device, $82 \%$ of surveyed practitioners comply with the literature's recommendations [2,5,9]. At the end of the canal preparation, irrigation with maximum efficiency is possible along the entire canal's length. This action optimizes the disinfection and the dissolution of organic materials. To achieve it, Arias-Moliz [15] suggests up to five minutes irrigation to better clean the whole canal space and make the cavity walls clean. This study's results show that $80 \%$ of surveyed practitioners perform a final irrigation in less than three minutes. This needs to be corrected to meet root canal irrigation's aims.

\section{Conclusion}

In their daily practice, Ivoriansomni-practitioners perform little endodontics. Sodium hypochlorite is the most commonly used solution for endodontic procedures, although many practitioners are not cognizant of the recommended concentration or dilution. This solution is often delivered using non-compliant devices, such as intramuscular injection needles and insulin syringes. Furthermore, they randomly use chelating agents. Practitioners generally do not do the final rinse as recommended. On the other hand, the refreshment frequency of the product meets the standards.

This study calls out to dental instructors to insist on therapeutic principles in general for a better quality of our therapeutics.

\section{References}

1. Ismail PM, Ahamed S, Sabiha PB, Sekhar MC, Moosani G, et al. (2016) Comparison of Sealer Penetration by Using Different Irrigation Techniques-An In-vitro Study. J Clin Diagn Res 10: 50-3.

2. Grayson I (2016) The Current State of Irrigation in Endodontics. J Mass Dent Soc 65: 32-3.

3. Urban K, Donnermeyer D, Schäfer E, Bürklein S (2017) Canal cleanliness using different irrigation activation systems: a SEM evaluation. Clin Oral Investig 21: 2681-7. 
4. Zand V, Lotfi M, Soroush MH, Abdollahi AA, Sadeghi M, et al. (2016) Antibacterial Efficacy of Different Concentrations of Sodium Hypochlorite Gel and Solution on Enterococcus faecalis Biofilm. Iran Endod J 11: 315-9.

5. Guivarc'h M, Ordioni U, Ahmed HM, Cohen S, Catherine JH, et al. (2017) Sodium Hypochlorite Accident: A Systematic Review. J Endod 43: 16-24.

6. Salem-Milani A, Zand V, Asghari-Jafarabadi M, Zakeri-Milani P, Banifatemeh A (2015) The effect of protocol for disinfection of extracted teeth recommended by center for disease control (CDC) on micro hardness of enamel and dentin. J Clin Exp Dent 7: e552-6.

7. Darcey J, Jawad S, Taylor C, Roudsari RV, Hunter M (2016) Modern Endodontic Principles Part 4: Irrigation. Dent Update 43: 20-2, 25-6, 28-30.

8. Gonçalves LS, Rodrigues RC, Andrade Junior CV, Soares RG, Vettore MV (2016) The Effect of Sodium Hypochlorite and Chlorhexidine as Irrigant Solutions for Root Canal Disinfection: A Systematic Review of Clinical Trials. J Endod 42: 527-32.

9. Zandi H, Rodrigues RC, Kristoffersen AK, Enersen M, Mdala I, Ørstavik D, et al. (2016) Antibacterial Effectiveness of 2 Root Canal Irrigants in Root-filled Teeth with Infection: A Randomized Clinical Trial. J Endod 42: 1307-13.

10. Silva PB, Krolow AM, Pilownic KJ, Casarin RP, Lima RK, et al. (2016) Apical Extrusion of Debris and Irrigants Using Different Irrigation Needles. Braz Dent J 27: 192-5.

11. Yost RA, Bergeron BE, Kirkpatrick TC, Roberts MD, Roberts HW, et al. (2015) Evaluation of 4 Different Irrigating Systems for Apical Extrusion of Sodium Hypochlorite. J Endod 41: 1530-4.

12. Duque JA, Duarte MA, Canali LC, Zancan RF, Vivan RR, Bernardes RA, et al. (2017) Comparative Effectiveness of New Mechanical Irrigant Agitating Devices for Debris Removal from the Canal and Isthmus of Mesial Roots of Mandibular Molars. J Endod 43: 326-331.

13. Sonntag D, Raab WH, Martin E, Keppel R (2017) Intracanal use of heated rinsing solutions: A pilot study. Quintessence Int 48:281-5.

14. Vatkar NA, Hegde V, Sathe S (2016) Vitality of Enterococcus faecalis inside dentinal tubules after five root canal disinfection methods. J Conserv Dent 19: 445-9.

15. Arias-Moliz MT, Camilleri J (2016) The effect of the final irrigant on the antimicrobial activity of root canal sealers. J Dent 52: 30-6.

16. Govindaraju L, Neelakantan P, Gutmann JL (2017) Effect of root canal irrigating solutions on the compressive strength of tricalcium silicate cements. Clin Oral Investig 21: 567-71.

17. De Gregorio C, Arias A, Navarrete N, Cisneros R, Cohenca N (2015) Differences in disinfection protocols for root canal treatments between general dentists and endodontists: A web-based survey. J Am Dent Assoc 146: 536-43.

18. Borzini L, Condò R, De Dominicis P, Casaglia A, Cerroni L (2016) Root Canal Irrigation: Chemical Agents and Plant Extracts against Enterococcus faecalis. Open Dent J 10: 692-703.

19. Zarra T, Lambrianidis T (2013) Percutaneous injuries amongst Greek endodontists: a national questionnaire survey. Int Endod J 46: $264-74$.

20. Chaudhry S, Yadav S, Talwar S, Verma M (2017) Effect of Endo Activator and Er, Cr: YSGG laser activation of Qmix, as final endodontic irrigant, on sealer penetration: A Confocal microscopic study. J Clin Exp Dent 9: 218-22.

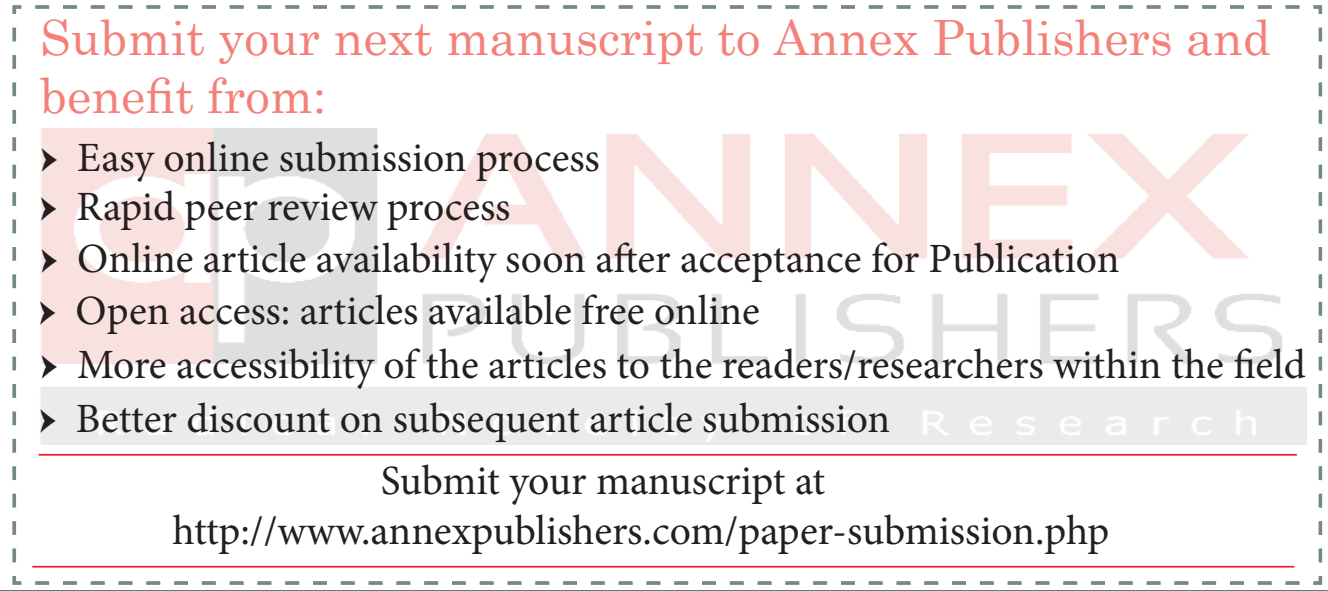

